\title{
BMJ Open Less than full-time training in surgery: a cross-sectional study evaluating the accessibility and experiences of flexible training in the surgical trainee workforce
}

\author{
Rhiannon L Harries, ${ }^{1}$ Vimal J Gokani, ${ }^{1}$ Peter Smitham, ${ }^{2} \mathrm{~J}$ Edward F Fitzgerald, ${ }^{1}$ \\ on behalf of the councils of the Association of Surgeons in Training and the British \\ Orthopaedic Trainees Association
}

To cite: Harries RL,

Gokani VJ, Smitham P, et al. Less than full-time training in surgery: a cross-sectional study evaluating the accessibility and experiences of flexible training in the surgical trainee workforce. BMJ Open 2016;6:e010136. doi:10.1136/bmjopen-2015010136

- Prepublication history for this paper is available online. To view these files please visit the journal online (http://dx.doi.org/10.1136/ bmjopen-2015-010136).

Received 30 September 2015 Revised 18 November 2015 Accepted 21 December 2015

CrossMark

\footnotetext{
${ }^{1}$ Association of Surgeons in Training Council, Association of Surgeons in Training, London, UK

${ }^{2}$ The British Orthopaedic Trainees Association, British Orthopaedic Association Offices, London, UK
}

Correspondence to Rhiannon L Harries; president@asit.org

\section{ABSTRACT}

Objectives: Generational changes in lifestyle expectations, working environments and the feminisation of the medical workforce have seen an increased demand in postgraduate less than full-time training (LTFT). Despite this, concerns remain regarding access to, and information about, flexible training for surgeons. This study aimed to assess the opinions and experiences of LTFT for surgical trainees. Design: Prospective, questionnaire-based crosssectional study.

Setting/participants: An electronic, self-administered questionnaire was distributed in the UK and Republic of Ireland through mailing lists via the Association of Surgeons in Training and British Orthopedic Trainee Association.

Results: Overall, 876 completed responses were received, representing all grades of trainee across all 10 surgical specialties. Median age was 33 years and $63.4 \%$ were female. Of those who had undertaken LTFT, 92.5\% (148/160) were female. Most worked $60 \%$ of a full-time post $(86 / 160,53.8 \%)$. The reasons for either choosing or considering LTFT were childrearing $(82.7 \%)$, caring for a dependent $(12.6 \%)$ and sporting commitments $(6.8 \%)$. Males were less likely to list childrearing than females $(64.9 \%$ vs $87.6 \% ; p<0.0001)$. Only $38 \%(60 / 160)$ found the application process easy and $53.8 \%$ (86/160) experienced undermining behaviour from workplace staff as a result of undertaking LTFT. Of all respondents, an additional $53.7 \%$ (385/716) would consider LTFT in future; $27.5 \%$ of which were male (106/385). Overall, only $9.9 \%$ of all respondents rated current LTFT information as adequate. Common sources of information were other trainees $(47.3 \%)$, educational supervisors $(20.6 \%)$ and local postgraduate school website (19.5\%).

Conclusions: Over half of surgical trainees working LTFT have experienced undermining behaviour as a result of their LTFT. Despite a reported need for LTFT in both genders, this remains difficult to organise, access to useful information is poor and negative

\section{Strengths and limitations of this study}

- This study describes the experiences of a crosssectional cohort of current surgical trainees who have, or who plan to, undertake less than fulltime training (LTFT) in surgery. High number of respondents helped provide a valid representation of the UK trainee cohort.

- The wide distribution of the survey in the UK and Republic of Ireland (ROI), and responses from all training grades, regions and specialties helped mitigate against focus on any one subgroup.

- However, all survey-based research is susceptible to responder bias.

- There is the potential for these results to reflect those with either poor or excellent experiences of LTFT who may have been more likely to respond.

- These results are also limited to experience in the UK and ROI; the degree to which this can be extrapolated to training in other countries is not known.

attitudes among staff remain. Recommendations are made to provide improved support and information for those wishing to pursue LTFT.

\section{INTRODUCTION}

Less than full-time training (LTFT) is postgraduate training undertaken while working a reduced number of hours, expressed as a percentage of full time; thus resulting in a relative lengthening in the number of years spent in medical training. In the UK, parttime postgraduate training was first introduced in the Oxford region in 1966 for married women, ${ }^{1}$ and was subsequently 
rolled out nationally. As a result, LTFT has become available across national postgraduate training schemes.

Funding for LTFT places is limited, and for a trainee to be eligible, there must be a 'well-founded reason' for not being able to work full time. Current guidelines state this must be either: ${ }^{2}$

- Disability or ill health, or being a carer for children or a ill or disabled partner, relative or other dependent; or

- Unique opportunities for personal or professional development (eg, sporting commitments, academia, quality improvement or leadership roles).

In recent years, numerous external factors have combined to influence medical training. The European Working Time Directive (EWTD) and US Duty Hour Regulations have dramatically changed working patterns, and generational changes in lifestyle expectations, working environments and the feminisation of the medical workforce have resulted in a gradual rise in demand for LTFT.

Across all specialties, in 2008, only $5.7 \%$ of the UK trainee doctor population were in LTFT, with the majority being female $(96 \%) .^{3}$ In comparison, this figure had risen to $11.3 \%$ by $2014 ;{ }^{4}$ of which $80.4 \%$ were female. This demonstrates both the increasing requirement for LTFT and the necessity for LTFT across both genders. This situation is not unique to the UK; over recent years, there has been a call for increased access to flexible working in order to attract or retain doctors, particularly females, in Europe ${ }^{5-7}$ North America, ${ }^{8-10}$ Asia, ${ }^{11}$ Australasia ${ }^{12-14}$ and Africa. ${ }^{15}$ Despite this, in the UK, there is evidence of variability in LTFT between both regions and specialty, ${ }^{16}$ and concerns have been raised regarding surgical trainees' access to this.

This study aimed to assess the experiences and opinions regarding access to LTFT posts and the adequacy of information available to current surgical trainees within the UK and Republic of Ireland (ROI).

\section{METHODS}

\section{Participants and setting}

Postgraduate surgical training within the UK and ROI consists of a minimum of 8 years of training following completion of the initial postqualification Foundation Programme or intern year, respectively. Competitive entry occurs prior to core and higher specialist training levels, with the exception of neurosurgery and cardiothoracic surgery, and trauma and orthopaedics in Scotland, where run-through training exists from appointment post-Foundation Programme. The Joint Committee on Surgical Training (JCST) is responsible for curriculum development and quality assurance of all the surgical training programmes in the 10 defined surgical specialties (cardiothoracic, general, maxillofacial, neurosurgery, orthopaedics and trauma, otolaryngology, paediatric, plastic, urology and vascular surgery). Core surgical knowledge is assessed by the Intercollegiate Membership of the Royal College of Surgeons (MRCS) examination, and specialty-specific knowledge during the later phase of higher surgical training is assessed by the Intercollegiate Fellowship of the Royal College of Surgeons (FRCS) examination. In 2015, there are 5323 surgical trainees in the UK and 438 surgical trainees in the ROI.

In the UK, approval for LTFT is given by the Trainee's Postgraduate Local Education and Training Boards (LETBs) in agreement with the Local Hospital Trust. LTFT is usually not less than $50 \%$ of full-time training, but can be less (to a minimum of $20 \%$ for up to 12 months) if agreed by all interested parties. ${ }^{17}$ The total duration of LTFT training time is calculated pro rata with full-time training. Funding for LTFT posts is provided by the Postgraduate LETBs (educational component of basic pay) and the local hospital (additional unsocial hours banding arrangement).

\section{Questionnaire design and distribution}

A novel 22-item questionnaire survey was developed, consisting of free text, binomial and five-point Likert scale responses. The questionnaire was designed with reference to previously published guidelines on questionnaire-based research. ${ }^{18}{ }^{19}$ The survey tool was peer reviewed by experienced trainers and piloted by over 20 surgical trainees with a spread of seniority and specialty. Content validity was ensured by this peer review and piloting process. Given the range of different constructs measured, internal consistency calculations were not undertaken. The feedback received was used to refine the question items. Individual question items were compulsory. No individually identifiable information was collected (eg, email address); therefore, nonresponders could not be identified for follow-up. No incentives were offered for participation.

A link to the online survey (SurveyMonkey.com, LLC, Palo Alto, California, USA) was distributed to members of the Association of Surgeons in Training (ASiT) and British Orthopedic Trainee Association (BOTA), surgical specialty associations, and local and national mailing lists. Data collection took place from 12 January 2015 to 9 March 2015. The ethical dimensions of this nonmandatory, anonymous evaluation survey were considered and no concerns were identified. Completion of the questionnaire was taken as implied consent to participate in this study.

This study was undertaken by ASiT (http://www.asit. org) and BOTA (http://www.bota.org.uk). ASiT is a pansurgical specialty professional body and registered charity working to promote excellence in surgical training for the benefit of junior doctors and patients alike. Originally founded in 1976, ASiT is independent of the National Health Service (NHS), Surgical Royal Colleges and specialty associations. BOTA is affiliated to the British Orthopaedic Association, and was established in 1987 to represent the views of orthopaedic trainees specifically. 


\section{Data analysis}

Only fully completed questionnaires were included in the analysis. Microsoft Excel (Microsoft, 2010, Redmond, Washington, USA) was used to calculate descriptive statistics. Statistical analysis was performed using Sigma Plot V.11 (Systat Software Inc, UK) and statistical significance was accepted at $\mathrm{p}<0.05$. Significance testing was performed using $\chi^{2}$ test for non-parametric binary data. Free-text responses were independently categorised by theme into groups for analysis by two of the authors, with differences resolved by discussion. Survey sample size calculations were based on standard published formulae. ${ }^{20}$

\section{RESULTS}

\section{Respondent demographics}

Of 1004 surveys submitted, a total of 876 were fully completed and included in the analysis. The mean age of respondents was 33 years (range 24-52) and $63.4 \%$ were female. Respondents ranged from first year Core Surgical Trainees to Post-Certificate of Completion of Training (CCT) fellowship trainees. Respondents were from all training regions within the UK and ROI and all 10 surgical specialties, with the largest percentage working in general surgery $(44.1 \%)$. A summary of demographics and responses by gender is provided in table 1 .

\section{Demand for flexible training}

Overall, 18.3\% (160/876) had previously undertaken or were currently taking LTFT during surgical training. Of those who had undertaken LTFT, $92.5 \%(148 / 160)$ were female and $7.5 \%(12 / 160)$ were male $(p<0.0001)$.
Regarding surgical specialty, $48.1 \% \quad(77 / 160)$ were general surgery trainees, with $13.6 \%(22 / 160)$ in ear, nose and throat (ENT) and $8.75 \%(13 / 160)$ in paediatric surgery. Of those who had taken LTFT, $92.5 \%$ (148/ 160) first took LTFT during higher surgical training, $6.25 \%(10 / 160)$ during core surgical training and $1.25 \%$ $(2 / 160)$ as a research fellow. The largest percentage of respondents reported first taking LTFT during higher specialty training (specialty trainee year 6, ST6) level $(44 / 160,27.5 \%)$, with the majority working $60 \%$ of a full-time post (86/160, 53.8\%; figure 1).

Of those respondents who had not previously undertaken LTFT, 53.7\% (385/716) would consider undertaking LTFT in the future; $27.5 \%$ of which were male (106/ $385)$. The reasons for either previously choosing or considering LTFT in the future were for childrearing $(82.7 \%)$, caring for a dependent $(12.6 \%)$, sporting commitments $(6.8 \%)$ and other reasons (21.2\%; figure 2). Other reasons were listed as being for: academia (17), ill health (4), humanitarian work (3) and leadership roles (2). Males were less likely to list childrearing when compared with females $(64.9 \%$ vs $87.6 \%$; $\mathrm{p}<0.0001)$.

\section{Experience of flexible training}

Of those who had previously undertaken LTFT, 53.8\% $(86 / 160)$ reported that they had experienced undermining behaviour from staff in the workplace as a direct result of their LTFT. The proportions reporting this were not statistically different between genders.

\section{Organisation and information}

Only 38\% (60/160) of those who had undertaken LTFT found the process of application for LTFT easy or very easy to organise. Considering all respondents, only $9.9 \%$

Table 1 Respondent demographics and responses by gender

\begin{tabular}{|c|c|c|c|c|c|c|}
\hline \multirow{3}{*}{$\begin{array}{l}\text { Question } \\
\text { Grade }\end{array}$} & \multicolumn{4}{|c|}{ What is your gender? } & \multirow{2}{*}{\multicolumn{2}{|c|}{$\begin{array}{l}\text { Total } \\
\text { (Gender combined) }\end{array}$}} \\
\hline & \multicolumn{2}{|c|}{ Female } & \multicolumn{2}{|c|}{ Male } & & \\
\hline & $\mathrm{n}$ & Total (\%) & $\mathbf{n}$ & Total (\%) & $\mathbf{n}$ & Per cent \\
\hline Higher trainee (ST3-ST4) & 98 & 11.2 & 59 & 6.7 & 157 & 17.9 \\
\hline Higher trainee (ST5-ST6) & 118 & 13.5 & 64 & 7.3 & 182 & 20.8 \\
\hline Higher trainee (ST7-ST8) & 97 & 11.1 & 68 & 7.8 & 165 & 18.8 \\
\hline Other & 43 & 4.9 & 25 & 2.9 & 68 & 7.8 \\
\hline \multicolumn{7}{|l|}{ Academic postholder } \\
\hline Yes & 29 & 3.3 & 24 & 2.7 & 53 & 6.1 \\
\hline \multicolumn{7}{|c|}{ Already undertaken LTFT during surgical training? } \\
\hline Yes & 148 & 16.9 & 12 & 1.4 & 160 & 18.3 \\
\hline Total responses & 555 & 63.4 & 321 & 36.6 & 876 & 100 \\
\hline
\end{tabular}




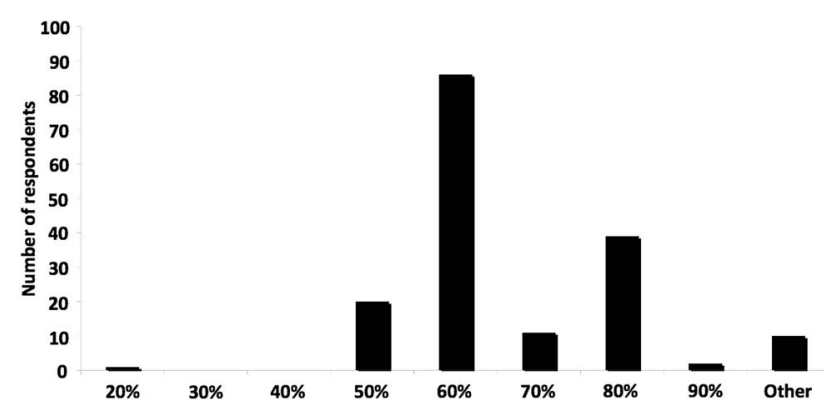

Figure 1 Distribution of responses for percentage of full time worked by LTFT trainees. LTFT, less than full-time training.

rated the current adequacy of information about LTFT as good or very good; with $89.5 \%$ noting that there needed to be more information to be available. Out of those who had either taken or were considering LTFT, the common sources of information used were other trainees $(47.3 \%)$, educational supervisors $(20.6 \%)$ and local training region websites $(19.5 \%)$.

\section{Qualitative analysis}

Qualitative comments were invited from respondents regarding their experience of LTFT. In the free-text comments box provided, 46 respondents described undermining or bullying behaviour by consultants and 17 described undermining or bullying behaviour by colleagues in relation to taking LTFT. Further qualitative analysis of these revealed major themes of issues with the on-call rota (14), receiving less operative exposure relative to time worked (11), negative affects on job rotations allocated by their training programme director (8), and that a full-time workload was still expected from them (5).

Respondents were asked to provide free-text comments on reasons why they would not chose LTFT. Of these, 77 respondents stated they had no reason or desire to undertake LTFT, and $70 \mathrm{did}$ not want to prolong their training, 53 felt that LTFT offered inferior training, 36 felt they would be disadvantaged or experience undermining behaviour if they undertook LTFT, 30 felt LTFT resulted in lack of continuity of patient care and 27 stated the reduction in pay would be an issue for them.

Respondents were asked how LTFT information, and the availability of this, could be improved. A breakdown of the major themes is provided in box 1 . Respondents also provided examples of their own views and experiences of LTFT in the free-text comment box. A representative sample of these is provided in box 2. The major themes included a lack of senior support for LTFT, lack of administrative support from hospitals, lack of information, impact on training, and negative attitudes and perceptions surrounding LTFT.

\section{DISCUSSION}

The results from this cross-sectional study indicate that over half of surgical trainees working LTFT have experienced undermining behaviour as a result of this, and that despite a reported need for LTFT in both genders, it remains difficult to organise, and the availability and accessibility of relevant information is poor.

Childcare was listed as the commonest reason for choosing or considering LTFT. Despite the growing number of female doctors in the UK, ${ }^{21}$ there is evidence to suggest that female doctors are under-represented at senior levels. ${ }^{22}{ }^{23}$ In 2008, 30\% of the trainees applying to core surgical training and $22 \%$ of those within higher surgical training programmes were female ${ }^{24}$; however, only $10 \%$ of all consultant (attending) surgeons are female. ${ }^{25}$ It has previously been suggested that women may decide not to continue with higher surgical training, as this is the stage in their life when childrearing occurs, ${ }^{24}$ it is therefore crucial that access to LTFT posts is improved to maintain the inevitably increasing female surgical workforce. In the UK, the General Medical Council (GMC) and National Working Group on Women in Medicine has recognised this issue and made recommendations for improved access to LTFT to encompass improved support for carers and those with young children. ${ }^{17}$ Similarly, In the ROI, the Health and Safety Executive (HSE) national flexible training scheme for higher specialist trainees has been launched
Figure 2 Reasons for previously choosing or considering LTFT in the future. LTFT, less than full-time training.

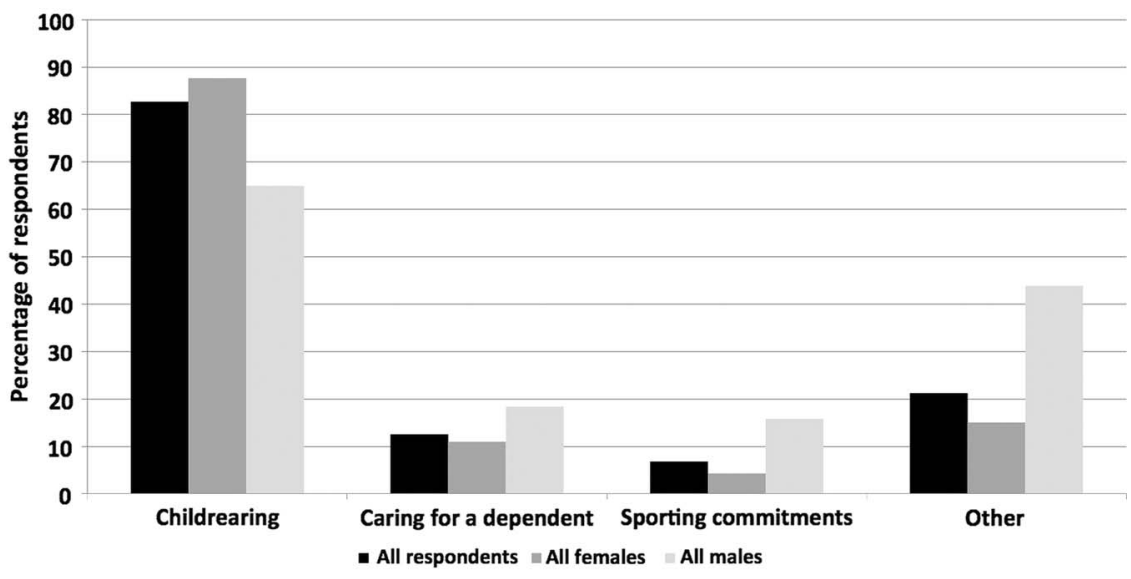


Box 1 Respondent recommendation to improve less than full-time training (LTFT) information and the availability of this

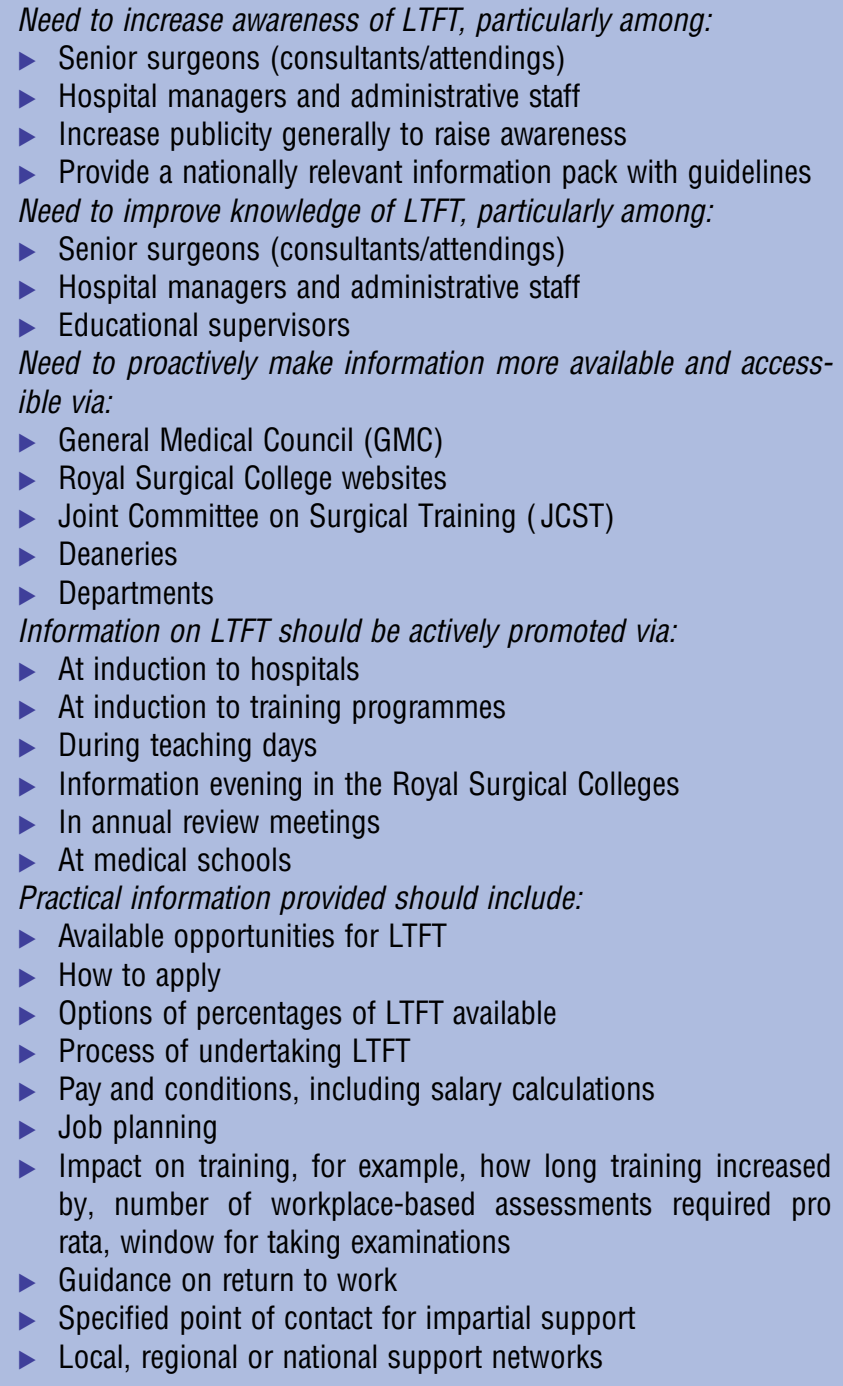

and is funded and managed by the HSE Medical Education and Training Unit. ${ }^{26}$

In this study, over $7 \%$ of LTFT trainees within surgery were male, a lower percentage in comparison to all medical specialties as a whole (19.6\%) in the 2014 GMC survey. ${ }^{4}$ However, our results confirmed a further $33 \%$ of male respondents would consider LTFT in the future, which is higher than the proportions of male trainees in Australasia and the USA, $26 \%$ and $13 \%$, respectively. ${ }^{10} 14$ Overall, surgical specialties have low numbers of LTFT trainees; in 2011, there were only 151 LTFT surgical trainees in the UK, ${ }^{27}$ and only $0.3 \%$ of surgical trainees in Australasia in a recent survey ${ }^{14}$ LTFT is relatively uncommon in surgery, possibly due to views of medical students and junior doctors that a career in surgery is not conducive to a good family life, ${ }^{28-32}$ and a lack of awareness that LTFT can be undertaken within surgery. It is imperative that education and encouragement should be provided to medical students throughout
Box 2 Representative qualitative comments from respondents regarding their less than full-time training (LTFT) experiences

"Seniors are poorly informed of process and opportunities for LTFT."

"I have found most support from nursing staff rather than fellow surgical colleagues."

"There is poor awareness of some of the technical challenges, planning and adaptations needed."

"I think trainees have a perception that it will negatively impact on their training."

"It's not the info itself it's the general attitude to flexitime training."

"Needs more senior support. Very little at present."

"Need to make it more acceptable...for men and women."

"Don't make women feel like a failure for considering it!"

"Surgery is very "go-go" and is difficult to take a step back without feeling inadequate."

"There is a stigma in surgery [to LTFT] which is frankly pathetic." "Once you become LTFT there is virtually no information/support on how to arrange logistically."

"It is easier to abandon [sporting] commitments, as the run-in time for competitive sport to declare the commitment means that you will not get a firm [LTFT] agreement in time."

"I have never felt that I have been treated differently clinically, but the administrative back-up is appalling and just creates a layer of unnecessary stress and logistical problems."

"I found it very easy to communicate with seniors about taking time out, but found talking to Human Resources departments and admin staff incredibly frustrating."

"There needs to be a widespread culture change in surgery which will enable more women to enter the profession and continue with it."

"There is a prevailing negative attitude towards LTFT training amongst older (esp male) consultants which make working and training LTFT much harder than it should be."

"You can provide service and have training, but one's progression is almost non-existent when you are working part-time."

"It is not really talked about as considered a taboo. I think information about perception and more discussion about it to consider it socially acceptable would be useful."

"[There need to be] seniors who do not guffaw at the potential option or say that it would just not be possible."

undergraduate training to raise awareness that LTFT can be compatible with surgical training. Role models (both female and male) are important in choosing surgical careers, ${ }^{33}$ and both training programme directors and educational supervisors should be aware of, and support the option of LTFT. The opportunities for this must be equally accessible for men and women.

Worryingly, $53.8 \%$ of those in LTFT posts reported undermining behaviour in the workplace as a perceived direct result of their LTFT. Qualitative analysis revealed bullying behaviour by consultants and colleagues. Undermining, bullying or harassment has no place within modern surgical training and is unacceptable. ${ }^{34}$ As professionals, surgical trainees have the right to feel valued and safe in the workplace, and are encouraged to 
raise concerns if undermining or bullying behaviour exists. Eight trainees also commented that their LTFT negatively affected job allocations with two respondents commenting "In ENT, head and neck jobs were not allocated to LTFT trainees" and another commenting "My training programme director said he would not waste a popular job on a LTFT trainee." The decision for job allocations should be based on the individual's learning needs and not on LTFT status; to do so is discriminatory. Another trainee commented that they had to share operating lists with another registrar at the same level of training. This damages the training of both, and such training experiences should be protected regardless of LTFT status.

Despite the increased need for LTFT within surgical training, only $38 \%$ found the application process easy and less than $10 \%$ rated the availability of information to help in the decision-making process as adequate. It is imperative that there is improved awareness and information to assist in the decision-making process.

\section{Recommendations}

Based on the qualitative feedback provided in this study, recommendations for improving awareness of LTFT, together with the content and availability of information provided, are summarised in box 1 . In addition to these practical points, numerous other wider issues were raised. Based on these, respondents recommended that there should be increased provision and funding for LTFT in surgical specialties for both genders. Information should be readily available for all surgical trainees wishing to or considering applying for LTFT, and ASiT has previously called for improved career counselling services to assist surgical trainees in successfully planning their careers. ${ }^{35}$ Both undergraduate and postgraduate training programmes should include career advice related to LTFT and surgical specialties. Individual departments and training regions should outline basic information including eligibility criteria and the application process as well as a point of contact for advice on their websites. Surgical colleges and specialty associations should also provide information on their websites. On a practical basis, having a LTFT adviser within each training region would help provide closer links with trainees and trainers on a local level, providing advice and easing ongoing challenges. Logistically, hospital human resource departments need to be aware of LTFT and support trainees undertaking this option. Finally, a wider cultural change is required to address negative perceptions of LTFT among both colleagues and seniors. Any trainee experiencing undermining or bullying behaviour as a result of these should report their concerns and have an identified LTFT mentor to support them.

\section{CONCLUSIONS}

Despite an increasing need for LTFT within surgical specialties, information regarding access to LTFT remains difficult to access. LTFT should be readily available to males and females within surgery, and improved information should be proactively provided for those considering LTFT, locally, regionally and nationally. Education and encouragement by the medical workforce is required in order to encourage those wishing to pursue LTFT in surgery specialties, and prevent negative attitudes surrounding LTFT posts.

Twitter Follow Rhiannon Harries at @rhiharries, Vimal Gokani at $@$ VimalGokani, Edward Fitzgerald at @DrEdFitzgerald and Peter Smitham at @PeteSmitham

Follow http://www.asit.org, http://www.bota.org.uk, http://twitter.com/ ASiTofficial @ASiTofficial, http://twitter.com/bota_uk @bota_uk

Acknowledgements The authors gratefully acknowledge the Royal College of Physicians and Surgeons of Glasgow (RCPSG), the Royal College of Surgeons of Edinburgh (RCSEd), and the Royal College of Surgeons of England (RCSEng) Women in Surgery group for distributing the survey to their trainee members. The authors additionally thank all those trainees who took the time to complete the survey.

Contributors RLH and JEFF conceived and designed the study. All authors designed the questionnaire. RLH collected the data. RLH and JEFF analysed the data. All authors were responsible for compiling the manuscript and approving the final article.

Competing interests The authors are current surgical trainees and elected members of the Executive of the Association of Surgeons in Training (Registered Charity No. 274841) or the British Orthopedic Trainees Association.

Provenance and peer review Not commissioned; externally peer reviewed.

Data sharing statement No additional data available.

Open Access This is an Open Access article distributed in accordance with the Creative Commons Attribution Non Commercial (CC BY-NC 4.0) license, which permits others to distribute, remix, adapt, build upon this work noncommercially, and license their derivative works on different terms, provided the original work is properly cited and the use is non-commercial. See: http:// creativecommons.org/licenses/by-nc/4.0/

\section{REFERENCES}

1. Rue R. Employment of married women doctors in hospitals in the Oxford Region. Lancet 1967;1:1267-8.

2. British Medical Association. Guide to Flexible Training. https://bma org.uk/developing-your-career/foundation-training/flexible-training/ reasons-for-flexible-training (accessed 18 Jun 2015).

3. Jones M, Montgomery J, Thomas S. Flexible training has matured. BMJ Careers. 2008. http://careers.bmj.com/careers/advice/ view-article.html?id=3062 (accessed 18 Jun 2015).

4. General Medical Council. GMC Training Survey. 2014. http://www. gmc-uk.org/NTS_2014_KFR_A4.pdf_56706809.pdf (accessed 18 Jun 2015).

5. Heuss LT, Haenggeli C. Open access to part-time specialist trainingthe Swiss experience. Swiss Med Wkly 2003;133 (263-6.

6. Jerg-Bretzke L, Limbrecht $K$. Where have they gone? A discussion on the balancing act of female doctors between work and family. GMS Z Med Ausbild 2012;29:Doc 19.

7. Kaderli R, Guller $U$, Muff $B$, et al. Women in surgery: a survey in Switzerland. Arch Surg 2010;145:1119-21.

8. Gordon MB, McGuinness GA, Stanton BF, et al. Part-time training in pediatric residency programs: principles and practices. Pediatrics 2008;122:e938-44.

9. Carling PC, Hayward K, Coakley EH, et al. Part-time residency training in internal medicine: analysis of a ten-year experience. Acad Med 1999;74:282-4.

10. Saalwachter AR, Freischlag JA, Sawyer RG, et al. Part-time training in general surgery: results of a web-based survey. Arch Surg 2006;141:977-82.

11. Nomura K, Yamazaki Y, Gruppen LD, et al. The difficulty of professional continuation among female doctors in Japan: 
a qualitative study of alumnae of 13 medical schools in Japan. BMJ Open 2015;5:e005845.

12. Mahady SE. Adding flexibility to physician training. Med J Aust 2011;194:460-2.

13. Henry A, Clements S, Kingston A, et al. In search of work/life balance: trainee perspectives on part-time obstetrics and gynaecology specialist training. BMC Res Notes 2012;5:19.

14. McDonald RE, Jeeves AE, Vasey CE, et al. Supply and demand mismatch for flexible (part-time) surgical training in Australasia. Med J Aust 2013;198:423-5.

15. Gardner SV, James MF, Evans NR. Gender issues among South African anaesthetists. S Afr Med J 2002;92:732-6.

16. Gray S, Alexander K, Eaton J. Equal opportunity for all? Trends in flexible training 1995-2001. Med Teach 2004;26:256-9.

17. General Medical Council. GMC Position Statement on less than full-time training. 2011. http://www.gmc-uk.org/Less_than_full_time_ training_GMC_position_statement_18_October_2011.pdf_ 45023470.pdf (accessed 18 Jun 2015).

18. Jones TL, Baxter MA, Khanduja V. A quick guide to survey research. Ann $R$ Coll Surg Engl 2013;95:5-7.

19. Eysenbach $\mathrm{G}$. Improving the quality of web surveys: the CHEcklist for Reporting Results of Internet E-Surveys (CHERRIES). J Med Internet Res 2004;6:e34.

20. Bartlett JE, Kotrlik JW, Higgins CC. Organizational research: determining appropriate sample size in survey research. Inf Technol Learn Perform J 2001;19:43-50.

21. General Medical Council. The state of medical education and practice in the UK. 2013. http://www.gmc-uk.org/20131004 Chapter_1_SoMEP.pdf_53706030.pdf (accessed 15 Jun 2015).

22. Dacre J, Shepherd S. Women and medicine. Clin Med 2010;10:544-7.

23. Taylor KS, Lambert TW, Goldacre MJ. Career progression and destinations, comparing men and women in the NHS: postal questionnaire surveys. BMJ 2009;338:b1735.
24. McNally S. Surgical training: still very competitive, but still very male. Ann R Coll Surg Engl 2012;94:53-5.

25. NHS Hospitals and Community Health Services. Medical and dental staff, England 1997-2007. Leeds, UK: The information Centre for Health and Social Care, 2008.

26. Guide to HSE National Flexible Training Scheme for Higher Specialist Trainees. 2013. http://www.rcsi.ie/files/surgery/docs/ 20140407123804_Guide to Flexible Training Nov.pdf (accessed 18 Jun 2015).

27. Department of Health. Workforce Census, 2011. https://catalogue.ic. nhs.uk/publications/workforce/numbers/nhs-staf-2002-2012-over/ nhs-staf-2002-2012-over-rep.pdf (accessed 29 Aug 2015).

28. Fitzgerald JE, Tang SW, Ravindra P, et al. Gender-related perceptions of careers in surgery among new medical graduates: results of a cross-sectional study. Am J Surg 2013;206:112-19.

29. Park J, Minor S, Taylor RA, et al. Why are women deterred from general surgery training? Am J Surg 2005;190:141-6.

30. Du J, Sthanathan J, Naden G, et al. A surgical career for New Zealand junior doctors? Factors influencing choice. $N Z$ Med J 2009;122:29-37.

31. Harris LM, Chaikof EL, Eidt JF. Altering the career choice: can we attract more women to vascular surgery? J Vasc Surg 2007;45:846-8.

32. Caniano DA, Sonnino RE, Paolo AM. Keys to career satisfaction: insights from a survey of women pediatric surgeons. J Pediatr Surg 2004;39:984-90.

33. Ravindra P, Fitzgerald JEF. Defining surgical role models and their influence on career choice. World J Surg 2011;35:704-9.

34. Association of Surgeons in Training. Undermining and bullying in surgical training. 2013. http://www.asit.org/assets/documents/UB_ Statement_ASiT_Final_2.pdf (accessed 18 Jun 2015).

35. Fitzgerald JEF, Giddings CEB, Khera G, et al. Improving the future of surgical training and education: consensus recommendations from the Association of Surgeons in Training. Int J Surg 2012;10:389-92. 